\title{
In vitro Anti-inflammatory Effect of Carthamus lanatus $\mathbf{L}$.
}

Saima Jalil ${ }^{\mathrm{a}}$, Bozhanka Mikhova ${ }^{\mathrm{b} *}$, Rilka Taskovac, Maya Mitova ${ }^{\mathrm{b}}$, Helmut Duddeck ${ }^{\mathrm{d}}$, Muhammad Iqbal Choudhary ${ }^{\mathrm{a}}$, and Atta-ur-Rahman ${ }^{\mathrm{a}}$

${ }^{a}$ H. E. J. Research Institute of Chemistry, International Center for Sciences, University of Karachi, Karachi-75270, Pakistan

b Institute of Organic Chemistry with Centre of Phytochemistry, Bulgarian Academy of Sciences, 1113 Sofia, Bulgaria. Fax: ++3592/8700225. E-mail: bozhana@orgchm.bas.bg

c Institute of Botany, Bulgarian Academy of Sciences, 1113 Sofia, Bulgaria

d Institute of Organic Chemistry, University of Hannover, 30167 Hannover, Germany

* Author for correspondence and reprint requests

Z. Naturforsch. 58c, 830-832 (2003); received May 30/July 17, 2003

The anti-inflammatory activity of four total extracts, their fractions and two main constituents ( $\alpha$-bisabolol $\beta$-D-fucopyranoside and luteolin 7-O-glucoside) of Carthamus lanatus $\mathrm{L}$. aerial parts, were assessed in vitro by determining the inhibitory effects on induced human neutrophils. The dichloromethane extract and its water-alcoholic part exhibited the most significant inhibitory effects.

Key words: Carthamus lanatus, Anti-inflammatory Activity, Neutrophils

\section{Introduction}

Inflammation is the reaction of living tissues to injury, infection or irritation. Bacterial infections cause an increased number of neutrophils, which produce an oxidative burst at the site of microbial invasion. The uncontrolled release of reactive oxygen species is assumed to be responsible for certain pathological conditions as heart attacks, septic shocks and rheumatoid arthritis. Administration of agents, which decrease the neutrophil accumulation in inflamed areas, might be a remedy in these cases. Carthamus tinctorius L. (Asteraceae) was shown to possess anti-inflammatory activity (Kasahara et al., 1994). The present paper deals with the in vitro anti-inflammatory effects of four total extracts (dichloromethane, methanol, 50\% methanol, water extracts), their fractions and two main constituents ( $\alpha$-bisabolol $\beta$-D-fucopyranoside and luteolin 7-O-glucoside) from Carthamus lanatus aerial parts.

\section{Experimental}

Plant material

C. lanatus aerial parts were collected in July, 2001 at the Losen region, Sofia, Bulgaria and identified by Dr. Rilka Taskova. A voucher specimen (SOM 156639) is deposited in the Herbarium of the Institute of Botany, Sofia.

\section{Extraction and isolation}

Dichloromethane extract. Air-dried and powdered aerial parts of $C$. lanatus $(500 \mathrm{~g})$ were extracted with dichloromethane. The residue of the dichloromethane extract (9.5 g) was partitioned between upper and lower layer (dry residue $4 \mathrm{~g}$ ) of hexane/methanol/water (19:19:2, v/v/v). $\alpha$-Bisabolol $\beta$-D-fucopyranoside $(0.9 \mathrm{~g})$ was isolated from the water/alcoholic phase of the dichloromethane extract by column chromatography on silica gel with hexane and hexane/ethylacetate (20:1 to $1: 10)$.

MeOH extract. C. lanatus $(500 \mathrm{~g})$; $\mathrm{MeOH}$ extract $(53 \mathrm{~g})$. The residue of the methanol extract was extracted subsequently with diethyl ether $(6 \mathrm{~g})$, ethyl acetate $(1.3 \mathrm{~g})$ and butanol $(3 \mathrm{~g})$; water soluble part $(37 \mathrm{~g})$. Luteolin 7 - $\mathrm{O}$-glucoside $(0.18 \mathrm{~g})$ was isolated from the butanol fraction by droplet counter current chromatography (DCCC), descending mode, with chloroform/methanol/water/ propanol $(9: 12: 8: 1, \mathrm{v} / \mathrm{v} / \mathrm{v} / \mathrm{v})$.

$50 \% \mathrm{MeOH}$ extract. C. lanatus (500 g); 50\% $\mathrm{MeOH}$ extract $(70 \mathrm{~g})$.

Water extract. C. lanatus $(100 \mathrm{~g}) ; \mathrm{H}_{2} \mathrm{O}$ extract $(15 \mathrm{~g})$.

$\alpha$-Bisabolol $\beta$-D-fucopyranoside and luteolin 7$O$-glucoside were identified by reported spectral data and comparison with reference compounds (Feliciano et al., 1990; El-Shaer et al., 1998). 


\section{Isolation of human neutrophils}

Human neutrophils were isolated by the modified method of Siddiqui et al. (1995). Briefly fresh heparinized blood collected from healthy volunteers was diluted with equal volume of Hanks balance salts solution (HBSS). After leaving $20 \mathrm{~min}$ at room temperature, the upper leukocyte layer was collected, layered over Ficoll paque (Pharmacia Biotech., Uppsala, Sweden) and centrifuged at $1500 \mathrm{rpm}$ for $30 \mathrm{~min}$. Cells were lysed with lysis buffer for $10 \mathrm{~min}$, centrifuged and diluted with HBSS. After centrifuging the pellet was resuspended in $\mathrm{HBSS}$ with $\mathrm{CaCl}_{2}, \mathrm{MgSO}_{4} \cdot 2 \mathrm{H}_{2} \mathrm{O}$ and $\mathrm{MgCl}_{2} \cdot 6 \mathrm{H}_{2} \mathrm{O}$. Cell counts were done using the improved Neubaur chamber. The viability of cells determined by the Trypan Blue method was above $97 \%$.

\section{Anti-inflammatory assay}

The anti-inflammatory effect was determined by the modified assay of Tan and Berridge (2000): total volume of $250 \mu \mathrm{l}$ modified Hank's Solution (MHS) with pH 7.4 containing $0.5-1.0 \times 10^{4}$ neutrophils/ml, $500 \mu \mathrm{M}$ WST-1 [1,2-(4-iodophenyl)-3(4-nitrophenyl)-5-(2,4-disulfophenyl)-2H-tetrazolium monosodium salt (Dojindo Laboratories, Kumamoto, Japan)] and various concentrations of the test samples. The control contained only buffer, neutrophils and WST-1. All samples were equilibrated at $37{ }^{\circ} \mathrm{C}$ and the reaction initiated by adding Zymosan-activated serum ZAS (Sigma Chemicals, St. Louis, USA) for $30 \mathrm{~min}$. Indomethacine was used as reference $\left(\mathrm{IC}_{50} 0.27 \mathrm{mg} / \mathrm{ml}\right)$. Absorbance was measured at $450 \mathrm{~nm}$ using Spectra MAX 340-plus microplate reader (Molecular Devices, Sunnyvale, California, USA). $\mathrm{IC}_{50}$ values were calculated by comparing with DMSO as blank and expressed as percent inhibition of superoxide produced.

\section{Statistical analysis}

Data are presented as the means \pm s.e.m. Statistical analysis was performed using EziFit 5.0 Windows based software after analysis of variance. P-values $<0.05$ were considered to be significant. $\mathrm{IC}_{50}$ values were calculated by regression line.

\section{Results and Discussion}

The anti-inflammatory effects of the test samples were assessed in vitro using the modified cellbased assay of Tan and Berridge (2000) based on reduction of the highly water-soluble tetrazolium salt WST-1 in the presence of activated neutrophils. The obtained data are summarized in Table $\mathrm{I}$. $\mathrm{IC}_{50}$ values of the most active fractions were calculated. The analysis revealed that the effect of the dichloromethane extract exceeded that of the more polar methanol, $50 \%$ methanol and water extract. The dry residues of the dichloromethane extract and its water/methanolic part showed the highest inhibitory effects: $70.5 \%$ and $81.3 \%$ with $\mathrm{IC}_{50}$ values $0.69 \mathrm{mg} / \mathrm{ml}$ and $0.47 \mathrm{mg} / \mathrm{ml}$, respectively. The water/alcoholic fraction is a complex mixture consisting of sesquiterpene fucosides, sterols, triterpenes, dehydroabietic acid, lipids and other constituents (Feliciano et al., 1990; Mitova et al., 2003). $\alpha$-Bisabolol $\beta$-D-fucopyranoside, being one of the main constituents of this fraction, showed $41.9 \%$ inhibitory effect and consequently, other constituents attribute to a higher extent to the total effect of this fraction. The active compounds of this fraction might be the sterols and triterpenes as shown for C. tinctorius (Kasahara et al., 1994). Furthermore, it is interesting to note that the significant anti-inflammatory effect of the

Table I. Inhibitory effect of extracts, fractions and individual constituents of $C$. lanatus on induced human neutrophils.

\begin{tabular}{lc}
\hline Sample & $\begin{array}{c}\text { Inhibition of } \mathrm{O}_{2}^{-} \\
\text {produced }(\%)^{\mathrm{a}}\end{array}$ \\
\hline $\mathrm{CH}_{2} \mathrm{Cl}_{2}$ extract & 70.5 \\
Hexane part & 6.3 \\
Water/methanolic part & 81.3 \\
$\mathrm{MeOH}$ extract & 28.9 \\
Diethyl ether fraction & 52.2 \\
EtOAc fraction & 37.3 \\
BuOH fraction & 17.7 \\
Water fraction & 19.0 \\
$50 \% \mathrm{MeOH}$ extract & 15.7 \\
$\mathrm{H}_{2} \mathrm{O}$ extract & 11.2 \\
$\alpha$-Bisabolol fucopyranoside & 41.9 \\
Luteolin-7-O-glucoside & 31.5 \\
Indomethacine & 72.2 \\
Control & 0 \\
\hline
\end{tabular}

a At a dose of $1 \mathrm{mg}$ of dry residue or constituent per $\mathrm{ml}$. 
water/alcoholic fraction is in correlation with the observed high antibacterial and cytotoxic activity of this fraction (Taskova et al., 2002).

The total methanol extract was more inhibitory than the $50 \% \mathrm{MeOH}$ extract and the water extract as observed for C. tinctorius flowers (Kasahara et al., 1994). The effect of the methanol extract is probably due to compounds present in the diethyl ether fraction $\left(52.2 \% ; \mathrm{IC}_{50} 0.94 \mathrm{mg} / \mathrm{ml}\right)$, which respectively are available also in the water/alcoholic part of the dichloromethane extract. The effects of the ethyl acetate fraction $(37.3 \%)$ and its

El-Shaer N., Shaaban E., Abou-Karam M., and El-Din A. (1998), Flavonoids from Carthamus lanatus. Alex. J. Pharm. Sci. 12, 23-26.

Feliciano A., Medarde M., Del Rey B., Del Corral J., and Barrero A. (1990), Bisabolane related glycosides from Carthamus lanatus. Phytochemistry 29, 645-648 (and ref. cited therein).

Kasahara Y., Kumaki K., Katagiri S., Yasukawa K, Yamanouchi S., Takido M., Akhisa T., and Tamura T. (1994), Carthami flos extract and its component stigmasterol, inhibits tumour promotion in mouse skin two-stage carcinogenesis. Phytother. Res. 8, 327-331.

Mitova M., Taskova R., Popov S., Berger R. G., Krings U., and Handjieva N. (2003), GC/MS analysis of some bioactive constituents from Carthamus lanatus L. Z. Naturforsch. 58c, 697-703. main constituent, luteolin 7-O-glucoside (31.5\%) were similar.

The present results show anti-inflammatory effect of $C$. lanatus and prove the pharmaceutical importance of this plant.

\section{Acknowledgements}

The authors are grateful to DFG, Germany for financial support, to the Fatmid Foundation for the supply of fresh blood and to Dr. Rafat A. Siddiqui (Methodist Research Institute, Indianapolis, USA) for help in the establishment of the bioassay.

Siddiqui R. A., English D., Harvey K., Cui Y., Martin M. I., Wentlands J., Akard L., Thompson J., and Garcia J. G. D. (1995), Phorbal ester-induced priming of superoxide generation by phosphotidic acid-stimulated neutrophils and granule-free neutrophils cytoplasts. J. Leukoc. Biol. 58, 189-195.

Tan S. and Berridge V. M. (2000), Superoxide produced by activated neutrophiles efficiently reduces the tetrazolium salt, WST-1 to produce a soluble formazan: a sample colorimetric assay for measuring respiratory burst activation and for screening anti-inflammatory agents. J. Immun. Meth. 238, 50-68.

Taskova R., Mitova M., Najdenski H., Tzvetkova I., and Duddeck H. (2002), Antimicrobial activity and cytotoxicity of Carthamus lanatus. Fitoterapia 73, 540543. 